\title{
Importance of Quaternary Prevention in the Frail Elderly
}

\author{
Nuria Orozco Mossi*, Gloria Rabanaque Mallén and Jorge Gabriel Gonzalez D’huicque \\ General practitioner and member of the group of infectious diseases SEMFYC of Valencia, Spain
}

*Corresponding author: Nuria Orozco Mossi, General practitioner and member of the group of infectious diseases SEMFYC of

Valencia, Spain

\begin{tabular}{l} 
ARTICLE INFO \\
\hline Received: 絊July 26, 2019 \\
Published: August 05, 2019 \\
\hline Citation: Nuria Orozco M, Gloria Ra- \\
banaque M, Jorge Gabriel Gonzalez D. \\
Importance of Quaternary Prevention \\
in the Frail Elderly. Biomed J Sci \& Tech \\
Res $20(2)-2019$. BJSTR. MS.ID.003431.
\end{tabular}

ABSTRACT

Keywords: Antipsychotic Agents; Frail Elderly; Patient Safety; Quaternary Prevention

Abbreviations: ADRs: Adverse Drug Reactions; EU: European Union; TIA: transient Ischemic Attack GP: General Practitioner; PCC: Primary Care Centre

\section{Introduction}

Adverse drug reactions (ADRs) are among the ten principal causes of morbidity and mortality worldwide, being those who cause hospitalization, rehospitalization or prolong hospital stay, those with greater economic and health impact [1]. In the EEUU ADRs are the 4th-6th cause of death, representing between 5 to $10 \%$ of all the causes of hospitalization and $15-20 \%$ of the total hospital Budget [1,2]. In November 2008, the European Union (EU) published the note "Strengthening pharmacovigilance to reduce adverse effects of medicines" which stated that $5 \%$ of the consultations in the emergency department are due to ADRs, what implies $€ 145.000$ of the health systems budgets. Furthermore, it is estimated that there are about 197.000 deaths per year in the EU related to ADRs [2]. In Spain, according to the study "Estudio sobre la seguridad de los pacientes en atención primaria” (APEAS) [3], 37\% of the reasons for serious consultation in primary health care centres are related to medication. Also, according to the Spanish report "Indicadores de Salud 2017" there was a mortality rate of 0.1 per 100,000 people due to ADRs between 2008 to 2015, being 45\% of the total deaths in patients over 75 years [4]. These data do not consider the avoidable adverse effects that did not caused mortality but are usually the result of inadequate prescriptions or over prescription.

The terms "quaternary risk" and "quaternary prevention" refer to those activities of the healthcare system such as pharmacotherapy or the performance of diagnostic tests that can cause damage, being sometimes unnecessary. Quaternary prevention has the purpose to avoid, reduce and palliate damages caused by these activities [5]. All these data highlight the importance of treatment optimization as an essential part in the follow-up of patient's pathologies, especially in elderly patients with greater complexity, due to pluripathology and polipharmacy but also because of the pharmacokinetic and pharmacodynamic changes that come with the age. These case emphasizes on the importance of considering drugs as an ethiopathogenic cause to be considered in any diagnostic process, and on the research and application of the available tools to try to avoid under and over prescription and the risk of generating ADRs, or prescribing inadequate medication.

\section{Case Report}

Our patient is 90 years old and has been a widower for 7 years, he is totally independent for daily life activities and has lived for years with his schizophrenic son in the family home. His son is stable with antipsychotic treatment prescribed by psychiatry and maintains a good relationship with him. In addition, the patient's daughter visits them weekly and does daily telephone supervision. In his medical record he suffers from a high blood pressure that is treated with Amlodipine, with good control of figures. He has an anxious depressive syndrome that causes insomnia for what he 
takes Citalopram and Lorazepam, and finally because of a transient ischemic attack (TIA) he suffered in 2013 he takes acetyl salicylic acid and Omeprazole. Sometimes he presents periods of constipation that are usually solved with dietary measures or Lactulose. The patient comes to our Primary Care Centre (PCC) with his son, who has noticed disorientation, drowsiness and dysarthric speech Besides, his son refers that the patient is walking with difficulty due to a balance disturbance. When asked, he does not refer history of infectious symptoms on previous days. We perform a complete examination, where there was normal temperature and glycemia, but he was hypotensive (70 / 50 mmHg) and bradycardic (46pm). We explore the bradypsychia and balance alteration referred by the son and as there was no other relevant data, we considered differential diagnosis between iatrogenic hypotension, confusional syndrome, transient ischemic attack, ADR or dehydration.

We referred the patient to the hospital`s emergency department where a cranial CT scan was performed, in which no acute changes were observed, other than those in relation to the TIA suffered in 2013, a complete blood analysis where there was only a slight normocytic anaemia of $13.1 \mathrm{~g} / \mathrm{dL} \mathrm{d}$ and a urine and a chest $\mathrm{x}$-ray without pathological findings. The patient was rehydrated in the emergency department for three hours with clinical recovery, deciding hospital discharge with observation and home control by his general practitioner (GP). Amlodipine was withdrawed, due to low blood pressure levels. That afternoon, the patient clinically improved, but presented next morning, a similar clinical picture. We were alerted on the phone and made a medical home visit where we reviewed the patient's medication exploring what and why he took each of his pills, verifying that he had been taking by mistake, his son's Paliperidone for his constipation. A bibliographic search was carried out [6] where it was verified that the medication taken by the patient had the following adverse effects: bradycardia, confusion, alterations of balance and dysarthria among other effects.

\section{Treatment}

The drug (Paliperidone) was suppressed and information on the use, possible ADRs and the importance of handling and preserving medication was given to the patient, and family members. Other information was provided, such as the usefulness of storing medicine in their original container to reduce the risk of mistakes with other drugs or the avoidance of splitting or crushing drugs without having consulted before about the possibility to do so. Keeping the original leaflet to be able to consult it in case of signs or symptoms that do not appear normal was also suggested. In addition, keeping medication away from other substances (cleaning products, medicines for animals), protected from light and heat is another useful measure.

\section{Discussion}

This case tries to emphasize on the risks of medication, especially in the elderly who are more susceptible to ADRs than other age groups. The elderly is usually a group with pluripathologies, high level of chronicity and polymedication, which is defined as the simultaneous intake of several drugs, with the cut generally set at five. This implies an increase in the probability of drug interactions and posology errors, a probable decrease in therapeutic adherence, and the possibility of generating "cascade prescriptions". This definition refers to the prescription of a drug to treat a symptom considered as primary and not as an adverse effect of another drug. An example would be to prescribe medication for a parkinsonism that manifests itself in a patient who has initiated metoclopramide, instead of identifying this symptom as an adverse reaction to this drug, whose treatment would consist in the suppression of the drug. The more drugs used, the more likely that adverse reactions occur and the higher the risk of hospitalization (regardless of age). This does not mean that drugs must not be prescribed when they are needed (adequate polypharmacy), but special attention should be paid when doing so, evaluating risks and benefits, as well as advantages and disadvantages of the prescription. There are different tools to help us practice adequate prescriptions and deprescription's. Beers and FORTA criteria, are the most widely used in the USA, and the STOPP-START criteria are most widely used in Europe, because the commercial active principles vary around $27-30 \%$.

The Beers criteria (updated this year) are the most widely used worldwide to consider the inadequate prescription of drugs in the elderly and divide drugs into 5 groups. They arouse in 1991 in order to point put inadequate prescriptions in nursing homes in the USA. They have been updated periodically and the latest update is from this year [7]. The FORTA criteria (Fit FOR The Aged) also arise in the USA but in 2014 and intend to add to the Beers criteria, those non-prescribed drugs that would be beneficial as well as the overtreatment and undertreatment of elderly patients [8]. The STOPP START criteria (Screening Tool of Older Persons' potentially inappropriate Prescriptions and Screening Tool to Alert doctors to Right Treatment), arise in Ireland in 2008, later they are assumed by the European society of geriatric medicine and validated by different countries among which is Spain. Last update in 2015. They classify drugs according to the different systems and perform two sections on when to start a drug and when we should suspend it [9]. With all this information the question is: How to optimize the prescription? Being well documented on the drug to be prescribed is an effective tool to try to reduce ADRs.

It is worth knowing a less extensive list of medicines and their indications and adverse reactions than prescribing without knowing the risks and benefits of them, especially paying attention to those drugs marketed for less time, where their adverse effects or behavior are not well known. These have the icon of a black triangle in the box in aim to monitor them and, declare any adverse effects that may occur. It is also convenient to assess on the therapeutic adequacy of drugs that may take a longer time to produce a relevant clinical benefit than the patient's life expectancy. Health education about possible benefits and risks associated with 
taking the new drug, as well as the purpose of the prescribed medication, also implies an active involvement of the patient in his treatment, improving therapeutic adherence and reducing possible posology errors. It is important that patients know the drugs by both brand names and trade names and that they avoid classifying them according to appearance, since in many cases the non-isoappearance between drugs can lead to confusion.

The term "isoappearance" refers all those drugs with the same active principle should have the same shape and colour, with the intention of avoiding errors derived from morphology and colour classification. Another interesting resource is to keep a list of the patient's active medication, trying to simplify posologies and give written instructions. The realization of tables with time distribution by meals allows them to have a more visual information on the posology to follow. In case they find it difficult, there is also the possibility of using pillboxes that avoid confusions when it comes to knowing if the patient has already taken the medication or not. From primary health care there is the ability to schedule patients to see the response obtained after the beginning of a new drug and the need to continue with previously prescribed drugs. The prescription for one month, can be made explaining that when it finishes the patient must come back so that the response to the treatment can be assessed before making long term prescriptions. In addition, it would be interesting to review patient's medication every six months and with the introduction of each new drug. Finally, transitions between hospitalization and primary care or specialized care and primary care are moments in which the patient is receiving a lot of information, which can lead to confusion and possible mistakes with the new treatment guidelines.

The number of doctors involved in the prescription of drugs to the same patient is considered an independent risk factor of ADRs. A study conducted in 2007 in Georgia with a cohort of 405 patients aged $>65$ years with a documented ADR in the last 6 months was selected. When the variables related to the possibility of generation of these were analysed, it was found that each doctor who intervened in the prescription of drugs for the same patient, increased de odds of reporting an ADR by 29\% (OR1.3 95\% CI, 1.0 -1.6). In addition, having 4-5 chronic pathologies doubled the possibility of having an ADR (OR 2.1 (95\% CI, 1-.1) and having 6 or more tripled it (OR 3.5 95\% CI,1.6-6.9) [10]. Consubstantial or inherent values in Primary Care with it's holistic, integral, integrated, longitudinal, permanent, universal and community approach give it a privileged position over the rest of the specialties when dealing with Quaternary risk.
In addition, it allows the Family Doctor to carry out quaternary prevention measures that favour pharmacological safety of the patient. The frequency of visits, the periodic controls of their chronic pathologies, the relationship of trust and closeness doctor-patient and the possibility of developing a individualized assistance plan in which the level of clinical complexity and the adequacy of the intervention levels are determined are things that can be done by Primary Care Doctors. The purpose is to avoid over, under or unsuitability of prescription and ultimately, ADRs. Not only the prescription is relevant, but also the deprescription when appropriate. "Sometimes you have to stop doing to make it better" as advocated by the movement of NOT TO DO by the Spanish Primary Health Care society SemFyC or worldwide choosing-wisely [11].

\section{Conflict and Acknowledgement}

The authors declare they have no conflict of interest concerning this article and no acknowledgement.

\section{References}

1. Avedillo Salas A, Reacciones Adversas a Medicamentos y la importancia de notificarlas. Colegio Oficial Farmacéuticos Zaragoza.

2. (2018) Strengthening pharmacovigilance to reduce adverse effects of medicines. European Commission.

3. Aranaz Andrés JM, Aibar C, Limón R, Mira JJ, Vitaller J, et al. (2012) study of prevalence of adverse event sin primary healthcare in Spain. Eur J Public Health 22(6): 921-25.

4. (2017) Ministerio de Sanidad, Servicios Sociales e Igualdad. Indicadores de Salud 2017. Evolución de los indicadores del estado de salud en España y su magnitud en el contexto de la Unión Europea. Madrid: Ministerio de Sanidad, Servicios Sociales e Igualdad.

5. Gérvas J, Enrique Gavilán Moral, Laura Jiménez de Gracia (2012) Prevención cuaternaria: es posible (y deseable) una asistencia sanitaria menos dañina. AMF 8(6): 312-317.

6. (2018) Paliperidona. AEMPS.

7. (2019) For Older People, Medications Are Common; Updated AGS Beers Criteria ${ }^{\circledR}$ Aims to Make Sure They're Appropriate, Too. AGS

8. Kuhn Thiel AM, Weiss C, Wehling M (2014) Consensus validation of the FORTA (Fit For The Aged) list: a clinical tool for increasing the appropriateness of pharmacotherapy in the elderly. Drugs Aging 31(2): 131-140.

9. O’Mahony D, O’Sullivan D, Byrne S, O’Connor MN, Ryan C, et al. (2015) STOPP/START criteria for potentially inappropriate prescribing in older people: version 2. 44(2): 213-218.

10. Green JL, Hawley JN, Rask KJ (2007) Is the number of prescribing physicians an independent risk factor for adverse drug events in an elderly outpatient population? Am J Geriatr Pharmacother 5(1): 31-39.

11. (2014) Elegir sabiamente. Choosing wisely. Recomendaciones no hacer. Docencia Alto Palancia. 
ISSN: 2574-1241

DOI: 10.26717/BJSTR.2019.20.003431

Nuria Orozco Mossi. Biomed J Sci \& Tech Res

(C) (P) This work is licensed under Creative Commons Attribution 4.0 License

Submission Link: https://biomedres.us/submit-manuscript.php

$\begin{array}{ll}\text { BIOMEDICAL } & \text { Assets of Publishing with us } \\ \text { RESEARCHES } & \text { - Global archiving of articles } \\ & \text { - Immediate, unrestricted online access } \\ & \text { - Rigorous Peer Review Process } \\ \end{array}$

